\title{
Atlantic SST gradient and the influence of ENSO
}

\author{
Huei-Ping Huang \\ Lamont-Doherty Earth Observatory of Columbia University, Palisades, New York, USA
}

Andrew W. Robertson

International Research Institute for Climate Prediction, Columbia University, Palisades, New York, USA

Yochanan Kushnir

Lamont-Doherty Earth Observatory of Columbia University, Palisades, New York, USA

Received 29 June 2005; revised 31 August 2005; accepted 12 September 2005; published 21 October 2005.

[1] The relationship between the boreal winter El Niño SST anomaly and boreal spring tropical Atlantic SST gradient (North Atlantic minus South Atlantic) is investigated using a long, detrended SST record. For both El Niño and La Niña, concordant cases (same sign for NINO3 index and Atlantic SST gradient) slightly dominate over discordant ones, reflecting the fact that the NINO3 index correlates more strongly with the North Atlantic than the South Atlantic SST anomaly. The ratio of the numbers of concordant and discordant cases is 4:3 overall, indicating strong non-ENSO influences on the Atlantic SST gradient. The composite of the concordant cases shows an SST anomaly in the North Atlantic with the same sign as NINO3 and an opposite-signed anomaly off the southwest coast of Africa resembling "Benguela Niño". That of the discordant cases is dominated by a pre-existing SST anomaly with the same sign as NINO3 in the south-central South Atlantic. Citation: Huang, H.-P., A. W. Robertson, and Y. Kushnir (2005), Atlantic SST gradient and the influence of ENSO, Geophys. Res. Lett., 32, L20706, doi:10.1029/2005GL023944.

\section{Introduction}

[2] The tropical Atlantic SST gradient, defined as the difference between North $\left(5^{\circ} \mathrm{N}-25^{\circ} \mathrm{N}\right)$ and South $\left(5^{\circ} \mathrm{S}-\right.$ $25^{\circ} \mathrm{S}$ ) Atlantic SSTs, is known to regulate precipitation anomalies over the northern Brazil. In March-May, a positive gradient (North Atlantic warmer than South Atlantic) suppresses Nordeste rainfall, similar to the effect of a positive El Niño SST anomaly [e.g., Giannini et al., 2004]. Giannini et al. [2004] found that, for 1950-1994, concordant cases (Atlantic SST gradient and NINO3 index having the same sign) dominate La Niñas while discordant cases dominate El Niños, resulting in a diminished impact of the latter on Nordeste rainfall. Building on this insight, the ENSO-Atlantic SST gradient relationship is revisited using a long and detrended SST data set.

[3] Previous studies, based mostly on the post-1950 SST data combined with model results, suggest that the NINO3 index in boreal winter is significantly (and positively) correlated with tropical North Atlantic SST anomalies (tNA) in boreal spring, while the correlation between NINO3 and South Atlantic SST anomalies (tSA) is generally weak [e.g., Enfield and Mayer, 1997; Chang et al.,

Copyright 2005 by the American Geophysical Union. 0094-8276/05/2005GL023944
1998; Alexander and Scott, 2002]. These studies also indicate strong non-ENSO influences on the seasonal-tointerannual variability of both tNA and tSA, with the former being suggested to be related to the variability of North Atlantic Oscillation and the latter the local air-sea interaction in the South Atlantic [e.g., Czaja et al., 2002; Chang et al., 1998]. In these contexts, the variability of tNA and tSA are often considered separately. Adopting the framework of Giannini et al. [2004] (hereinafter referred to as G2004) but using a much longer SST record, in this study we will consider both tNA and tSA and re-examine the relationship between ENSO and the Atlantic SST gradient as envisaged by G2004. The contributions of the preconditions in tNA and tSA to the gradient in boreal spring will be discussed.

\section{Data and Methods}

[4] The newly available HadISST1 data set [Rayner et al., 2003] is used. A 10-year high pass filter is applied to the 1870-2004 time series of SST at each grid point to remove trends but retain interannual variability. The original data with $1^{\circ} \times 1^{\circ}$ resolution is further interpolated onto a $128 \times$ 64 Gaussian grid. This resolution is slightly higher than the $5^{\circ} \times 5^{\circ}$ of Kaplan SST data used by G2004. For 19501994, the main results of G2004 are recovered using our data set, if the SST is undetrended as in that work.

[5] The North and South Atlantic SST indices, tNA and tSA, are defined in the same way as by G2004. The boxes chosen for the spatial averaging of SST anomalies for tNA and tSA are indicated in Figure 1a. The Atlantic SST gradient is defined as G1 = tNA - tSA. We will focus on the relationship between the March-May average of tNA, tSA, or G1 and the preceding December-January average of NINO3 SST anomaly. These choices are meaningful as the Atlantic SST gradient has its maximum impact on Brazilian rainfall in boreal spring (G2004), while the correlation between the Dec-Jan NINO3 index and the tNA SST anomaly is known to peak at about 4-month lag with tNA lagging NINO3 [e.g., Enfield and Mayer, 1997] (see also Figure 2). The 1876-1997 segment of the detrended monthly SST anomaly is used for the ensuing analyses.

[6] Before proceeding further, it is useful to mention that the tNA and tSA regions are among those with a better coverage of ship measurements of SST in the pre-WWI era [e.g., Woodruff et al., 1987]. In the HadISST1 data set, the variance of SST represented by these in-situ measurements 

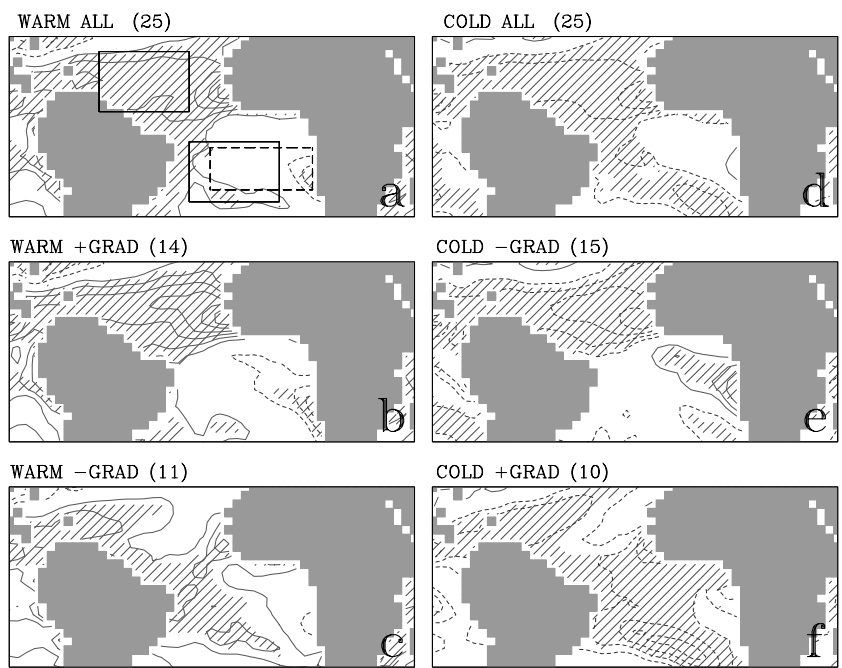

COLD - GRAD (15)

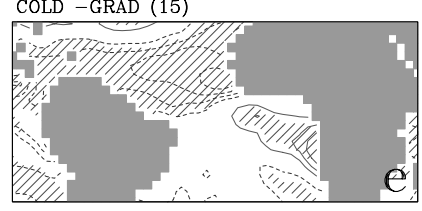

COLD + GRAD (10)

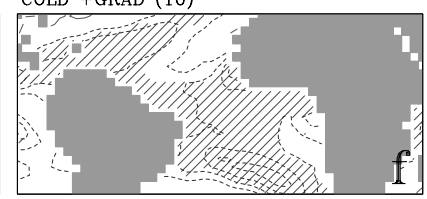

Figure 1. The composites of Mar-May SST anomaly based on the Dec-Jan NINO3 index. (a) All warm ENSO events. (b) Warm events with a concordant Atlantic SST gradient, $\mathrm{G} 1=(\mathrm{tNA}-\mathrm{tSA})>0$. (c) Warm events with $\mathrm{G} 1<$ 0. (d) All cold events. (e) Cold events with a concordant gradient, G1 < 0 . (f) Cold events with G1 >0. The boxes with a solid frame in Figure 1a are used to defined tNA and tSA. The one with dashed frame defines tSA2 (see text). Contour interval is $0.1^{\circ} \mathrm{C}$. Solid and dashed are positive and negative, with zero contours omitted. Areas with the SST signal at a $95 \%$ or higher level of statistical significance, based on t-test, are shaded. The boundaries of the 3 boxes in Figure $1 \mathrm{a}$ are $\left(5^{\circ} \mathrm{N}, 25^{\circ} \mathrm{N}, 60^{\circ} \mathrm{W}, 30^{\circ} \mathrm{W}\right)$ for tNA, $\left(25^{\circ} \mathrm{S}\right.$, $\left.5^{\circ} \mathrm{S}, 30^{\circ} \mathrm{W}, 0^{\circ} \mathrm{E}\right)$ for tSA, and $\left(21^{\circ} \mathrm{S}, 7^{\circ} \mathrm{S}, 25^{\circ} \mathrm{W}, 10^{\circ} \mathrm{E}\right)$ for tSA2. See color version of this figure in the HTML.

down to $\sim 500 \mathrm{~km}$ scales is preserved by blending the largescale structures of SST (obtained by the Reduced Space Optimal Interpolation technique) and the non-interpolated (but quality-controlled) in-situ data [see Rayner et al., 2003, section 3]. The variability in tNA and tSA in the early period is not an artifact of the large-scale smoothing and interpolation.

\section{Results}

\subsection{Concordant Vs. Discordant Cases}

[7] Figure 1 shows the composite maps of March-May SST anomalies from the major El Niño (Figure 1a) and La Niña (Figure 1d) years for 1876-1997. A warm year (boreal spring season) is included in the composite if the preceding Dec-Jan NINO3 index is greater than $0.75^{\circ} \mathrm{C}$, a cold year if it is less than $-0.75^{\circ} \mathrm{C}$. These choices result in an equal number (25 each) of El Niño and La Niña years for 18761997. With more samples used in this study, the asymmetry between cold and warm ENSO events documented by G2004 for 1950-1994 disappears. Both are slightly dominated by concordant cases. In other words, more often than not, tNA is greater than tSA for El Niño, while the opposite is true for La Niña. Quantitatively, 14 out of 25 El Niño and 15 out of 25 La Niña years are concordant. The composites of SST anomalies for the concordant cases for warm and cold events are shown in Figures $1 \mathrm{~b}$ and 1e, and discordant cases in Figures 1c and 1f. For all cold and warm events, the ratio of the numbers of concordant and discordant cases is $29: 21$, or approximately $4: 3$, indicating still strong nonENSO influences on the SST gradient.

[8] Combining cold and warm events to maximize the number of samples, and adopting the null hypothesis that concordant and discordant cases have equal chance of occurrence during an ENSO year, the probability (by a straightforward summation of the binomial distribution) that 29 or more concordant cases are obtained from a random sample of 50 events is 0.16 . This gives just an $84 \%$ confidence level to reject the null hypothesis. However, as an indication that the NINO3-G1 relationship may be real, this level of significance does hold - and actually increases - if one chooses only the strongest ENSO events with $|\mathrm{NINO} 3|>$ $1.0^{\circ} \mathrm{C}$. Among the 24 of them, 16 are concordant and 8 discordant, with $(\mathrm{W}+, \mathrm{W}-, \mathrm{C}+, \mathrm{C}-)=(10,4,4,6)$. (Here, $\mathrm{W}$ and $\mathrm{C}$ indicate warm and cold events and + and - the sign of G1.) The significance level for the above-mentioned test is now 92 percent. Since this is about the best one can get with the existing data, further progresses on the problem might have to be assisted by models.
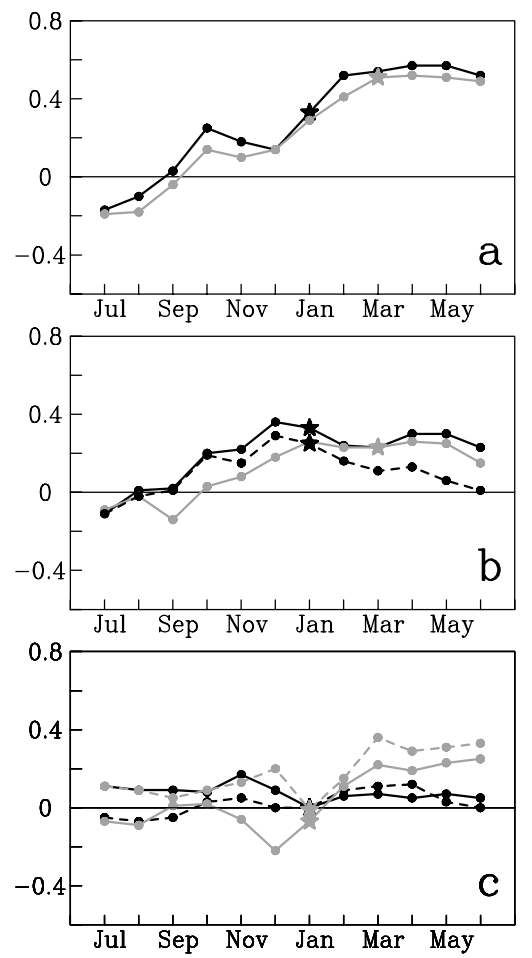

Figure 2. (a) The correlation Cor(NINO3,tNA) with NINO3 in January(1) (black) and March(1) (gray) chosen as base points to correlate with tNA in all months of the year, defined as July(0)-June(1). (b) Same as Figure 2a but for Cor(NINO3,tSA). The dashed curve is Cor(NINO3,tSA2) with January(1) as the base point for NINO3. (c) Same as Figure 2a but for Cor(tNA,tSA) (solid black), Cor(tSA,tNA) (dashed black), and Cor(NINO3,G1) (solid gray) with January chosen as the base point for tNA, tSA, and NINO3, respectively. The gray dashed curve is also Cor(NINO3,G1) but with the correlation calculated for the major ENSO years. Except for this curve, all other curves in Figures $2 a-2 c$ are based on all years from 1876-1997. The base point in each curve is marked with a star. 


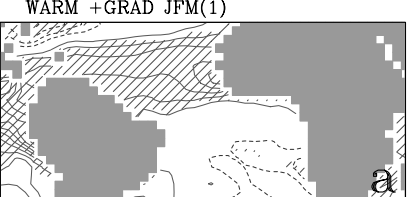

WARM - GRAD JFM(1)
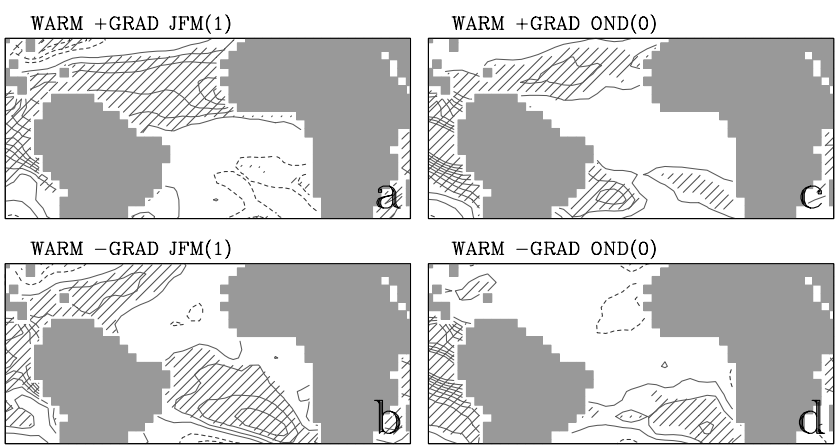

WARM - GRAD OND $(0)$

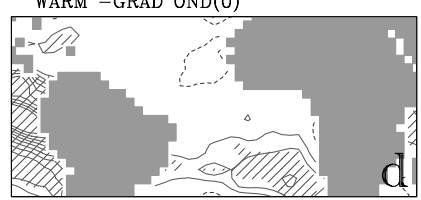

Figure 3. Same as Figure 1 but for (a) January-March of year 1, warm concordant cases, (b) January-March of year 1, warm discordant cases, (c) October-December of year 0, warm concordant cases, (d) October-December of year 0 , warm discordant cases. See color version of this figure in the HTML.

[9] All El Niño and La Niña events that satisfy the criterion, $|\mathrm{NINO} 3|>0.75^{\circ} \mathrm{C}$ for December-January average, are used in the preceding analysis regardless of the magnitude of G1 in March-May. Inevitably, some events with an extremely small G1 are included in counting the numbers of concordant and discordant cases. To test if our results are robust, the analysis is repeated by rejecting the cases with $|\mathrm{G} 1|<0.1^{\circ} \mathrm{C}$. Of the original 50 major ENSO years (warm and cold), 38 remain with 21 concordant and 17 discordant. The concordant:discordant ratio is approximately preserved.

[10] While the composite maps in Figure 1 broadly resemble their counterparts by G2004, a notable difference exists in the emergence of a well-defined structure of SST anomaly, having the opposite sign of NINO3 index, off the coast of Angola in our concordant cases (Figures 1b and 1e). This SST signal is statistically significant at above $95 \%$ level, as indicated by the shading in Figure 1. This structure resembles the SST anomaly associated with "Benguela Niño" [e.g., Florenchie et al., 2004]. The concordant cases are those with a warm (cold) ENSO event coinciding with a cold (warm) Benguela Niño event. The Benguela Niño-like structure did not stand out in the composites of G2004, possibly because strong Benguela Niño events do not occur as frequently as El Niño [e.g., Florenchie et al., 2004]; The 44-yr period used by G2004 contains only a small number of strong Benguela Niño events, even fewer of them occur during selected ENSO years.

\subsection{Correlation Between NINO3 and (tNA,tSA)}

[11] Figures $2 \mathrm{a}$ and $2 \mathrm{~b}$ show the correlation, based on the 1876-1997 period (using all 122 years), of the NINO3 index of January and March of "year 1" with the monthly tNA and tSA through the year, defined as July(0)-June(1). Consistent with previous studies [e.g., Enfield and Mayer, 1997; Chang et al., 1998], at a 4-month lead, the January NINO3 index is more strongly correlated with tNA (correlation $=0.57$ for March-May average) than tSA (correlation $=0.28)$. The correlation between tSA and NINO3 peaks at the end of year 0 , then declines afterward. If only the major ENSO years (those selected for Figure 1) are used, the behavior of the correlation between January NINO3 and
March-May (tNA, tSA) remains similar but with an enhanced correlation (not shown). For example, Cor(NINO3,tNA) increases from 0.57 for all years to 0.72 for major ENSO years. The stronger correlation between NINO3 and tNA is consistent with the slight dominance of concordant cases. The gray curves in Figure $2 \mathrm{c}$ show the correlation between the NINO3 index in January and G1 in all months, for all (solid) and major ENSO (dashed) years from 1876-1997. The correlation is positive throughout boreal spring (correlation coefficient averaged over MarchMay is 0.21 for all years, 0.32 for ENSO years).

[12] The black curves in Figure 2c show the correlation of January tNA with the tSA of all months (solid), and the reciprocal of it with January tSA as the base point correlating with tNA in other months (dashed). Both indicate a negligible correlation between tNA and tSA. In particular, the preconditions in tNA and tSA in winter (that may affect the gradient, G1, in spring) are uncorrelated. Note that if one takes each spring season as one degree of freedom, the 122 yrs of data implies a minimum correlation of 0.17 for 95\% significance.

[13] It should be mentioned that the values of correlation discussed above are somewhat sensitive to the choice of the box for defining tSA. From Figure 1a, the weak positive correlation between January NINO3 and March-May tSA in Figure $2 b$ is contributed by the SST anomalies off the coast of South America and in the south-central South Atlantic that are partially covered by the tSA box. Should one move the box northeastward, as indicated by the box in Figure 1a with dashed frame that defines an alternative SST index, tSA2, the correlation of January NINO3 index and March-May tSA2 drops to an insignificant 0.1 , as shown in Figure $2 b$ (dashed). This sensitivity reflects the fact that ENSO has different impacts on the SSTs in the eastern, western, and south-central South Atlantic. In contrast, the impact of ENSO on the tropical North Atlantic SST is more uniform (having one sign) in longitude.

\subsection{Benguela Niño and South Atlantic SST}

[14] As pointed out by G2004, the sign of G1 in the ENSO composites generally persists from late winter to spring, such that the concordant and discordant cases shown in Figure 1 can be considered as being influenced by a precondition of the same sign of G1 in late winter. It is interesting to track the composite maps through the spring season to show the time evolution of the Atlantic SST anomalies. Figures $3 \mathrm{a}$ and $3 \mathrm{~b}$ are the same as Figures $1 \mathrm{~b}$ and $1 \mathrm{c}$ but with the composites for January-March. Figures $3 \mathrm{c}$ and $3 \mathrm{~d}$ are the same but for October-December of year 0 . The counterparts of Figure 3 for cold events exhibit similar patterns but with the opposite sign (not shown). Due to the persistence of the sign of G1, the years used for the composites in Figure 3 are the same as those for Figure 1. The sequence of Figures $3 \mathrm{a}$ and $1 \mathrm{~b}$ indicate that, for the warm concordant cases, the cold Benguela Niño-like SST anomaly has a South Atlantic origin and stays in roughly the same location during spring. Equally interesting is the sequence of Figures $3 \mathrm{~d}, 3 \mathrm{~b}$, and $1 \mathrm{c}$. Here, a strong preexisting positive SST anomaly in the far-south South Atlantic combined with a negligible tNA characterize the precondition of the warm discordant cases. If this precondition in the South Atlantic SST is strong enough in boreal 
winter, as shown in Figures $3 \mathrm{~b}$ and $3 \mathrm{~d}$, subsequent influences of ENSO (warming up of tNA following El Niño) may not be enough to overturn the negative G1 in boreal spring. Similar composites showing the preconditioning by the South Atlantic SST were given by G2004. Clearly, the precondition in the South Atlantic is as important as that in North Atlantic in determining the tropical Atlantic SST gradient in boreal spring. This point is recently explored by Barreiro et al. [2004].

[15] Florenchie et al. [2003, 2004] have recently investigated the life cycle of Benguela Niño using post-satellite SST data and an ocean model. Some post-1980 Benguela Niño events are found to have been triggered by sea level height disturbances in the equatorial Atlantic that propagate eastward and southeastward before manifesting itself in the SST anomaly in the Benguela region. This scenario is not evident in the sequence of our Figures $3 \mathrm{c}, 3 \mathrm{a}$, and $1 \mathrm{~b}$. However, it remains a question whether or not the life cycle presented by Florenchie et al., based on a handful of Benguela Niño events, is "canonical". It should also be stressed that, since Benguela Niños do not occur synchronously with El Niños [e.g., Florenchie et al., 2004], the SST anomalies in the Benguela region in our ENSO composites (Figures 1 and 3) do not necessarily reflect the canonical signal in boreal spring for the strongest Benguela Niños.

\section{Summary and Further Remarks}

[16] The relationship between the December-January El Niño SST anomaly and March-May tropical Atlantic SST gradient is analyzed with a long and detrended SST data set. It is found that concordant cases slightly dominates for both El Niño and La Niña. Combining all major warm and cold events for 1876-1997, the ratio of the numbers of concordant and discordant cases is about 4:3, indicating a still strong presence of non-ENSO influences. The composite of the concordant cases contains an SST anomaly in the tropical North Atlantic having the same sign as NINO3 index, and an opposite-signed SST anomaly off the southwest coast of Africa resembling Benguela Niño. The composite of discordant cases is characterized by an SST anomaly in the south-central South Atlantic with the same sign as NINO3, and a very weak tropical North Atlantic SST anomaly. For the discordant cases, this pattern already exists in late winter and the subsequent influences of ENSO in spring are not enough to overturn the discordant SST gradient.

[17] Although our analyses indicate that the asymmetry between warm and cold ENSO events (i.e., dominance of discordant cases for El Niño) found by Giannini et al. [2004] is specific to the period from 1950-1994, the framework laid out by these authors, namely, using the preconditions in tNA and tSA to predict G1 and Brazilian rainfall, remains potentially useful. An immediate future work would be to quantify the contributions by ENSO and local preconditions in controlled hindcast experiments. Our results here indicate that the precondition in the South Atlantic SST may be as important as that in the North Atlantic SST in determining the Atlantic SST gradient, thereby the Brazilian rainfall anomaly, in boreal spring. The patterns of the SST anomalies pertinent to the preconditions in the South Atlantic are more complicated than those in the tropical North Atlantic. The origins of these South Atlantic SST anomalies, especially their relationship with Benguela Niño and the variability of the South Atlantic anticyclone, deserve further investigations.

[18] Acknowledgments. The authors thank Michael Alexander and an anonymous reviewer for useful comments. This work is supported by the NOAA CLIVAR-Atlantic Program and is funded in part under the CICAR award number NA03OAR4320179 from NOAA, U. S. Department of Commerce. Kushnir is supported by NSF grant ATM-0347009.

\section{References}

Alexander, M., and J. Scott (2002), The influence of ENSO on air-sea interaction in the Atlantic, Geophys. Res. Lett., 29(14), 1701, doi:10.1029/2001GL014347.

Barreiro, M., A. Giannini, P. Chang, and R. Saravanan (2004), On the role of the Southern Hemisphere atmospheric circulation in tropical Atlantic variability, in Earth's Climate: The Ocean-Atmosphere Interaction, Geophys. Monogr. Ser., vol. 147, edited by C. Wang, S.-P. Xie, and J. Carton, pp. 143-156, AGU, Washington, D. C.

Chang, P., L. Ji, H. Li, C. Penland, and L. Matrosova (1998), Prediction of tropical Atlantic sea surface temperature, Geophys. Res. Lett., 25, $1193-$ 1196.

Czaja, A., P. van der Vaart, and J. Marshall (2002), A diagnostic study of the role of remote forcing in tropical Atlantic variability, J. Clim., 15, 3280-3290.

Enfield, D. B., and D. A. Mayer (1997), Tropical Atlantic sea surface temperature variability and its relation to El Nino-Southern Oscillation, J. Geophys. Res., 102, 929-945.

Florenchie, P., J. R. E. Lutjeharms, C. J. C. Reason, S. Masson, and M. Rouault (2003), The source of Benguela Niño in the South Atlantic Ocean, Geophys. Res. Lett., 30(10), 1505, doi:10.1029/2003GL017172.

Florenchie, P., C. J. C. Reason, J. R. E. Lutjeharms, M. Rouault, C. Roy, and S. Masson (2004), Evolution of interannual warm and cold events in the southeast Atlantic Ocean, J. Clim., 17, 2318-2334.

Giannini, A., R. Saravanan, and P. Chang (2004), The preconditioning role of tropical Atlantic variability in the development of the ENSO teleconnection: Implications for the prediction of Nordeste rainfall, Clim. Dyn., $22,839-855$

Rayner, N. A., D. E. Parker, E. B. Horton, C. K. Folland, L. V. Alexander, D. P. Rowell, E. C. Kent, and A. Kaplan (2003), Global analyses of sea surface temperature, sea ice, and night marine air Temperature since the late nineteenth century, J. Geophys. Res., 108(D14), 4407, doi:10.1029/ 2002JD002670.

Woodruff, S. D., R. J. Slutz, R. L. Jenne, and P. M. Steuer (1987), A comprehensive ocean-atmosphere data set, Bull. Am. Meteorol. Soc., $68,1239-1250$

H.-P. Huang and Y. Kushnir, Lamont-Doherty Earth Observatory of Columbia University, 61 Route 9W, Palisades, NY 10964, USA. (huei@1deo.columbia.edu; kushnir@ldeo.columbia.edu)

A. W. Robertson, International Research Institute for Climate Prediction, Columbia University, 61 Route 9W, Palisades, NY 10964, USA. (awr@iri.columbia.edu) 